\title{
Corporate Digital Entrepreneurship: Leveraging Industrial Internet of Things and Emerging Technologies
}

\author{
Swapan Ghosh, Mathew Hughes, Paul Hughes, \\ and lan Hodgkinson
}

\begin{abstract}
Industrial firms are under severe pressure to innovate by leveraging the industrial Internet of things (IIoT) and emerging digital technologies. Digital entrepreneurship for existing organizations (corporate digital entrepreneurship) is a key differentiating factor in a highly competitive and disruptive environment. However, there is limited guidance for corporate digital entrepreneurship and industrial managers do not have a conceptual framework to navigate their organizations for new product and process innovation. This paper discusses the importance of emerging digital technologies for digital entrepreneurship and presents a conceptual framework of corporate digital entrepreneurship highlighting three elements-business model transformation, operating model transformation, and cultural transformation-which is necessary for fostering digital entrepreneurship in organizations. The chapter presents three case studies and discusses practical implications for the future.
\end{abstract}

\footnotetext{
S. Ghosh (ه)

Menlo College, Atherton, California, USA

e-mail: swapan.ghosh@menlo.edu

M. Hughes · I. Hodgkinson

Loughborough University, Loughborough, UK

P. Hughes

De Montfort University Leicester, Leicester, UK

(C) The Author(s) 2021

M. Soltanifar et al. (eds.), Digital Entrepreneurship, Future of Business and Finance,

https://doi.org/10.1007/978-3-030-53914-6_10
} 


\section{The Relevance of the Topic}

Innovation and entrepreneurship are intertwined and most often entrepreneurship starts with innovation by an individual or group of people (Gustavsson et al. 2018). The great economist Schumpeter suggested that entrepreneurship by individuals or by a large firm could drive the innovation and growth of a firm (Schumpeter 1934). In corporate entrepreneurship terms, acts of entrepreneurship (or intrapreneurship within the boundaries of the firm) and innovation are needed to perpetuate and sustain an organization over time (Kraus et al. 2018; Hughes and Mustafa 2017). Despite considerable scholarly discussion about entrepreneurship, we must increasingly pay attention to digital technologies and its profound impact on entrepreneurship (a phenomenon termed "digital entrepreneurship") (Nambisan et al. 2017) as we traverse the new industrial revolution. The practitioners have started multiple digital transformation initiatives; however, they have limited guidelines for fostering entrepreneurship in a large organization.

The Fourth Industrial Revolution (Industry 4.0) and the industrial Internet of things (IIoT) are fundamentally changing the industrial landscape, and digitization of businesses is driving innovation and change in organizations (Kagermann et al. 2014). We are also moving from the Fourth Industrial Revolution to the Fifth Industrial Revolution (Industry 5.0), where man and machine will be integrated seamlessly to deliver business outcomes and artificial intelligence (AI) will bring the Fifth Industrial Revolution. ${ }^{1}$ Digital (corporate) entrepreneurship in large organizations using digital technology is more important now than a decade ago. For example, businesses must anticipate and address digitization in business and corporate strategies (Mithas et al. 2013; Kohli and Grover 2008), revise organizational design (Sund et al. 2016), and must implement new digital technologies (Setia et al. 2013) and generate new capabilities (Tripsas and Gavetti 2000) to innovate new value propositions (Krotov 2017), or else be left behind. As appropriately surmised by Bill Ruh, former CEO of GE Digital, "if you cannot master the idea of digital inside your business, you are opening the door for commoditization." By leveraging industrial IoT and other digital technologies such as artificial intelligence (AI), machine learning (ML), blockchain, big data/analytics, managers, and corporate entrepreneurs can accelerate business transformation, which in turn will optimize the organizational productivity and increase customer satisfaction. Industrial IoT requires new business models and the concepts of digital entrepreneurship and traditional entrepreneurship are merging together for industrial businesses.

This chapter discusses how large and established companies are accelerating corporate digital entrepreneurship by leveraging industrial IoT and emerging technologies.

\footnotetext{
${ }_{1}^{1}$ https://www.robotics.org/blog-article.cfm/What-is-Industry-5-0-and-How-Will-IndustrialRobots-Play-a-Role/99.

${ }^{2}$ https://www.forbes.com/sites/maribellopez/2018/01/24/ge-digital-ceo-shares-insights-on-digitaltransformation-in-industrial-markets/\#23e4b1fe3385.
} 


\section{Background}

There is a plethora of academic studies positioning the meaning and intent behind entrepreneurship Schumpeter (1934) viewed the entrepreneur as a leader and contributor to the process of creative destruction. Kirzner (1985) suggested that entrepreneurs mostly fulfill unsatisfied needs in the market or improve operational efficiency by detecting and closing gaps in the marketplace. In recent times, views have emerged that highlight the uncertainty under which entrepreneurs must make judgments about assembling resources and mobilizing partners and markets (Foss, Klein and Bjørnskov 2018). Digitization and Industry 4.0 are symptomatic of a context characterized by fundamental uncertainty and asymmetric information. Perhaps the most significant challenge to large organizations in this context is the inability to foresee which business models will be the most profitable, what capabilities are needed into the long-term, and what the customer and competitive landscapes will consist of. This is all the more apparent which are industry boundaries blur, and non-traditional entities become modern-day competitors (e.g., consider Apple, Dyson, and Google) all making investments in autonomous vehicles versus the classic top car manufacturers (VW, Toyota, Renault Nissan, GM, Hyundai Kia, Ford, Honda, Fiat Chrysler, Suzuki, PSA Peugeot Citroen, BMW, and Mercedes-Benz).

Digital entrepreneurship can be thought of as an extension of the traditional entrepreneurship model; however, there are some distinct differences. The process of marketing products and services, workplaces and coordination between stakeholders are different in the digital entrepreneurship model (Hafezieh et al. 2011). E-commerce business models exist for a couple of decades (Turban et al. 2006; Mahadevan 2000) where business models support business-to-business (B2B) and business-to-consumer (B2C) models and most of the companies developed their own e-commerce platforms (e.g., ebay.com, Alibaba.com, etc.). However, with technological advancements and cloud computing, platform-based business models have emerged and platform owners have more power than the factory owners in the early industrial revolution. For example, Amazon Web Services (AWS), Salesforce.com, and other platform vendors provide software platforms to build different e-commerce solutions quickly for a larger customer base. The platform economy has helped a new set of entrepreneurial companies like Airbnb, Uber, Lyft to connect consumers with service providers.

According to Hull et al. (2007), value creation is the core purpose of entrepreneurship, where digital entrepreneurship is a subcategory of entrepreneurship where most or all of the products and services are digitized. Hair et al. (2012) suggested that market orientation is important for digital entrepreneurship and electronic community and communication play an important role for successful digital ventures. Giones and Brem (2017) further divided entrepreneurship into three categories: Technology Entrepreneurship characterized by new products based on innovative and breakthrough research and development, Digital Technology Entrepreneurship where new products are based on information and 
communication technology (ICT), and Digital Entrepreneurship where new products and services are developed by leveraging the Internet, Cloud, Big Data/Analytics and other emerging technologies. Sussan and Acs (2017) believe that digital entrepreneurship is any venture (social, government, or corporate) where digital technologies are used for developing products and services for customers.

\subsection{Corporate Digital Entrepreneurship/Intrapreneurship}

Corporate entrepreneurship is implemented in the firm either through corporate venturing (internal, cooperative, or external corporate venturing) or through strategic entrepreneurship, where a company invests in innovation activities for competitive advantage; however, these innovations may or may not result in new business (Morris et al. 2010). Other researchers suggest that corporate entrepreneurship includes a firm's innovation activities, venturing, and renewal activities (Ling et al. 2008). Corporate entrepreneurship is also a higher-order capability/construct based on a firm's ability in innovation, venturing, and renewal activities (Ling et al. 2008).

Corporate entrepreneurship is typically used synonymously with Intrapreneurship and is defined as entrepreneurship within an existing organization (Antoncic and Hisrich 2001), commensurate with innovation practices within an organization by which employees undertake and pursue different business opportunities (Ward and Baruah 2014). Ping et al. (2010) suggest that intrapreneurship fosters every aspect of business innovation and create new business benefits for organizations. Intrapreneurship initiatives can help a company to develop new businesses by innovating new products and services (Knight 1997; Stopford and Baden-Fuller 1994; Zahra 1993) or by entering new markets and customer segments (Zahra 1991) or both. These efforts can alter the course of the business and revitalize its business performance.

For the remainder of this chapter, corporate digital entrepreneurship is used in lieu of corporate entrepreneurship and intrapreneurship from a digitization viewpoint. Corporate digital entrepreneurs play important roles in bringing industrial Internet of things (IIoT) and emerging technology-based business applications to the market and create new business models using their technical knowledge, business expertise, and relationships with ecosystem partners. These entrepreneurs connect the dots between technological, business, ethical and legal issues and create a business environment where they can develop new products and services (Krotov 2017). As with any other innovation, technology-based innovations can be classified into three categories: incremental, revolutionary (integrative), and disruptive (Christensen et al. 2005). For example, GE Healthcare developed GE Centricity ${ }^{\mathrm{TM}}$ imaging collaboration suite in the cloud. ${ }^{3}$ This is an example of incremental

\footnotetext{
${ }^{3}$ https://www.gehealthcare.com/products/healthcare-it/enterprise-imaging/centricity-imagingcollaboration-suite.
} 
innovation over GE's in-hospital Centricity imaging solution. Now, the hospital can store healthcare-related images in the cloud and clinicians (general physicians, radiologists, specialists) and patients can share and collaborate effectively in a cloud-based environment. The scope of the incremental innovation is mostly restricted to existing customers and markets. On the other hand, GE Healthcare also developed a GE health cloud, ${ }^{4}$ where hospitals, patients, and related services can store comprehensive health information (imaging, monitoring, electronic medical record, etc.) for patients. This is an example of a revolutionary (integrative) innovation. This type of integrative innovation is enterprise-wide and mostly creates new customers and markets. GE Healthcare also developed a handheld pocket-sized ultrasound machine ${ }^{5}$ using a smartphone and intelligent probes. This machine can collect ultrasound images for a patient and securely transfer the image to a health cloud or in-house hospital imaging system. This is a moderately low cost, high utility machine for developing countries and represents an example of disruptive innovation, which creates new markets and expands the business rapidly. Corporate digital entrepreneurs in large organizations develop products and services by leveraging these three categories of innovations. These innovative solutions use IoT-based applications and digital technologies for data management and analysis.

\subsection{Impact of Industrial loT and Emerging Technologies}

Application of industrial IoT and digital technologies is disrupting industrial businesses, and this external pressure can stimulate entrepreneurship within incumbent organizations. "Industrial Internet" is a term coined by General Electric (GE) (Leber 2012) and comprises of connecting together industrial machines to share information on a real-time or near real-time basis and to make proactive and predictive business decisions based on machine analytics. Leber (2012) further suggests that the industrial Internet can change the entirety, or at least substantially, the business paradigms of industrial businesses, which in turn will help a company to develop new products and processes faster, improve productivity, and increase customer satisfaction. There is a convergence of industrial systems with the power of advanced processing and analysis capabilities, the emergence of low-cost cloud-based data sharing environments, and low-cost sensing and machine data sharing. These business solutions are transforming the industrial world and in turn will change our daily lives, including the ways we do our jobs and business. For example, GE aviation and Pivotal have created a data analytics solution where they can track 3 million flights, gather 300 terabytes of data and analyze the data 2000 times faster than the previous methods and reduce cost tenfold (Schneider 2014).

\footnotetext{
${ }^{4}$ https://www.gehealthcare.com/products/health-cloud-platform.

${ }^{5}$ https://www.gehealthcare.com/products/ultrasound/vscan-family/vscan.
} 
Siemens healthcare has developed a digital ecosystem store in the cloud where Siemens and its partners are sharing healthcare applications and the customers can subscribe to those applications on a pay-per-use basis. ${ }^{6}$

This holds the promise of greater productivity, a higher standard of living and a safe and secure industrial environment. The savings from interconnected and intelligent machines will be substantial for the global market. For example, in fifteen years globally, improving fuel savings by just one percent in the aviation industry could save $\$ 30$ billion, one percent of fuel savings in power generation equipment could save $\$ 66$ billion, one percent of operation costs of hospitals could save $\$ 63$ billion, one percent increase in transportation efficiency could save \$27 billion, and one percent improvement in capital utilization in upstream and downstream oil exploration and development could save $\$ 90$ billion (Evans and Annunziata 2012). So, the power of just one percent improvement is substantial for industrial companies and these five industries alone could save \$276 billion globally in fifteen years. The corporate entrepreneurs can utilize the digital ecosystems and develop new products and services and bring those to the market much faster than their competitors.

The problems facing firms are twofold, though. First, which companies will gain as technologies shift, new technologies emerge and are implemented, and new business models emerge is uncertain. Established, incumbent businesses are struggling with historical investments in capabilities and ways of doing business that has developed a dependency and reinforced by years if not decades of investments. Second, established, incumbent businesses must embrace entrepreneurial and digital mindsets to set a willingness to innovate into new, non-traditional technologies, the ability to both do so and execute on which requires hitherto undefined capabilities. As firms cannot make infinite investments, strategic decisions on markets and capabilities are judgments couched in uncertainty, which calls on incumbent firms to embrace corporate digital entrepreneurship. For example, Pitney Bowes Inc. (www. pitneybowes.com) is a nearly century-old office postage meter company in Stamford, CT, USA. The company's annual revenue is around $\$ 3.5$ billion. In 2014, Pitney Bowes realized that office postage meter and printing businesses were changing and customers were more interested in digital transactions. The corporate digital entrepreneurship initiative was started by Roger Pilc, then chief innovation officer, ${ }^{7}$ who realized that Pitney Bowes should reposition itself as a technology company and should leverage emerging technologies such as IoT, big data, mobile, and cloud technologies. They developed a commerce cloud (software-as-a-service, SaaS) solution and diversified their business in cross-border e-commerce. In 2018, half of the revenue came from commerce services. ${ }^{8}$

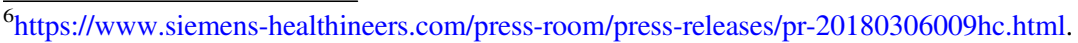

${ }^{7}$ https://www.forbes.com/sites/peterhigh/2016/08/09/roger-pilc-awakens-pitney-bowes-innovationengine/\#1a32078f603d.

${ }^{8}$ https://www.investorrelations.pitneybowes.com/static-files/faba498e-408f-4085-87ae-fc815edbc061.
} 


\subsection{Elements of Digital Entrepreneurship}

From the above discussion, we can infer that digital technologies and interconnected ecosystems have a profound impact on digital entrepreneurship as companies are developing new ways to do business, manage their internal operations differently, and have developed new ways to interact with their partners. For example, disruptive technologies such as 3D printing technologies could help in business model innovation as it allows rapid prototyping and mass customized products based on unique fulfillment requirements for the customers (Rayna and Striukova 2016). These mass customized products could initiate new enterprise ventures. In the dotcom era, business model innovations were started by the start-up companies by developing advertisement-based business models as digital technologies changed the value creation models (Abd Aziz et al. 2008), however in the current situation, established companies must transform their business models and initiate new ventures by developing new products and services so that they can compete in the connected ecosystem (Burmeister et al. 2016).

As companies are changing their business models, they need to change their operating models as well as needing the next-generation operating models for the digital world (Bollard et al. 2017). As business models are changing, companies are developing new operating models to support their business models (Berman and Hagan 2006). Researchers (Reijnen et al. 2018) have suggested an operating model canvas (OMC) approach such as based on business model innovation. A company can develop an OMC model that visualizes value proposition, primary and supporting business activities, channels and actors responsible for such activities. Thus, digital technologies are impacting existing operating models and by realigning operating models with business models, companies can be engaged in the new ventures.

Other than business models and operating models, the mindsets of the managers, which transform organizations culturally, are equally important to be successful as digital entrepreneurs. The mindsets of the executives and top managers influence strategic changes (Adner and Helfat 2003). As industrial businesses are expanding their digitization efforts, companies are redrawing their industry boundaries and developing new and innovative ways to deliver services to their customers (Kaganer et al. 2014). According to these authors, digital leadership is not a job title or a role, but a mindset of managers responsible for digital entrepreneurship. The cognition capability is an important attribute of top managers (Finkelstein et al. 2009). Smith and Tushman (2005) suggest that top managers need to build "paradoxical cognition" that enables them to pursue exploration and exploitation simultaneously.

Digital disruptions and emerging technologies are influencing a firm's ability to change its business models, operating models, and culture which is in turn fostering digital entrepreneurships, and these transformations lead to new ventures. 


\section{Technologies}

Fig. 1 Conceptual framework for corporate digital entrepreneurship

\section{Conceptual Model/Empirical Findings}

Emerging digital technologies (Industrial IoT, AI/ML, Blockchain, etc.) foster digital entrepreneurship by providing a disruptive solution development paradigm so that new and existing companies develop new products and services across multiple industries by leveraging these technologies (Lee and Lee 2015). IoT provides new opportunities for innovation (Krotov 2017), whereas artificial intelligence (AI) has a significant impact on the economy as it is being considered a "method for invention" which positively changes the innovation processes within an organization and the roles of R\&D within that organization (Cockburn et al. 2018). AI/ML-based technologies are helping digital entrepreneurship in medical technologies including expert system guided medical diagnosis (Cockburn et al. 2018), home health care (Augusto et al. 2007), intensive care unit applications (Hanson and Marshall 2001). Outside healthcare, AI/ML-based applications are accelerating digital entrepreneurship in manufacturing, retail, and other industrial businesses. By utilizing IoT, AI/ML, and other Internet technologies, manufacturers have developed proactive preventive maintenance solutions for their machines and they are offering product-as-service business models to their customers. ${ }^{9}$ IoT and $\mathrm{AI} / \mathrm{ML}$ serve as a boon for retail companies as they collect huge amounts of customer data from different customer interactions, analyze the data using machine learning techniques, and provide new and enhanced customer-centric solutions including highly structured web shops, intelligent in-store bots, and online chatbots (Fig. 1). ${ }^{10}$

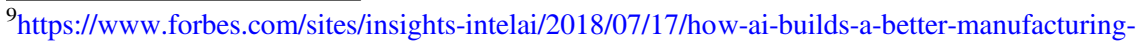
process/\#38a799f01e84.

${ }^{10} \mathrm{https} / / /$ medium.com/datadriveninvestor/how-ai-will-change-the-retail-industry-in-2019c817091c6306.
} 
As mentioned in the previous sections, industrial organizations are changing their business models and developing outcome-centric business models, which are possible due to technological advancements. Since organizations are venturing into new markets and customers, they are transforming their operating models by integrating business systems and processes with internal systems and with ecosystem partners. Finally, organizations are transforming their cultures and developing digital cultures for entrepreneurship. However, external factors such as competitive turbulence, market turbulence, technology turbulence, and internal factors such as path dependency and digital commitment influence these factors. The following sections describe these three factors and influencers.

\subsection{Business Model Transformation}

Corporate digital entrepreneurs are developing new products and services by transforming existing business models and introducing new ones. Value creation and value capture are two fundamental functions of a business model. Teece (2010) suggests that the purpose of a business model is to define how the company delivers value to its customers, entices its customers to pay for those perceived values, and converts those payments to profit for the company. Teece further suggests that business model innovation can be a path to competitive advantage if it is sufficiently differentiated from its competitors and cannot be replicated easily. Hui (2014) highlights the importance of digital business model innovation for IoT businesses. The author emphasizes that in the connected world, companies need to rethink how values are created and captured for their customers. Hui (2014), in the Harvard Business Review article entitled "How the Internet of Things Changes Business Models", describes the value creation and capture model and identifies the capabilities needed to create and capture values for IoT business. Value creation is related to the offerings provided by companies to their customers so that they are encouraged to use the service and to pay for those services. Earlier competition was based on features and, since new features add incremental value for customers, most of the business models were based on price. However, in the connected world, products are never sold once as the companies collect the usage of the products on a continuous basis and tweak the products based on customer requirements. This is a continuous improvement process and one that embraces services aligned to products. As with value creation, Hui suggests that the value capture model is changing. Companies are not relying on the one-time value of their products and services, but on recurring values captured from their customers. This is becoming possible due to real-time connectivity with customers. Table 1 (adapted from Hui 2014) describes the model and how emerging technologies are helping to transform the business models.

A business model developed by one company in one market segment can be implemented in another company in a different segment (Teece 2009). For example, a subscription-based software services model pioneered by Salesforce.com's platform is being adopted by GE Digital in its Predix, Industrial Internet platform. 
Table 1 Value creation/capture analysis

\begin{tabular}{l|l|l|l}
\hline $\begin{array}{l}\text { Value } \\
\text { models }\end{array}$ & $\begin{array}{l}\text { Factors for } \\
\text { value } \\
\text { creation/capture }\end{array}$ & Traditional business model & $\begin{array}{l}\text { IoT and technology-based } \\
\text { business model }\end{array}$ \\
\hline $\begin{array}{l}\text { Value } \\
\text { creation }\end{array}$ & Customer needs & $\begin{array}{l}\text { To solve existing problems } \\
\text { (reactive) }\end{array}$ & $\begin{array}{l}\text { To address the current and } \\
\text { future needs proactively }\end{array}$ \\
\cline { 2 - 4 } & Offerings & $\begin{array}{l}\text { To market products with service } \\
\text { contracts }\end{array}$ & To market products as-a-service \\
\cline { 2 - 5 } & Role of data & $\begin{array}{l}\text { To maintain customers by } \\
\text { collecting data periodically for } \\
\text { future product enhancements }\end{array}$ & $\begin{array}{l}\text { To enhance customer } \\
\text { satisfaction by continuous } \\
\text { monitoring of customers }\end{array}$ \\
\hline Palue & Path to profit & $\begin{array}{l}\text { To develop and maintain sales } \\
\text { capabilities for one-time sale of } \\
\text { the product and service }\end{array}$ & $\begin{array}{l}\text { To enhance sales capabilities for } \\
\text { recurring pay-per-use revenue }\end{array}$ \\
\cline { 2 - 5 } & Control points & $\begin{array}{l}\text { To protect using IP protection, } \\
\text { brand values, and customer } \\
\text { support }\end{array}$ & $\begin{array}{l}\text { To protect using personalization } \\
\text { and network effects }\end{array}$ \\
\cline { 2 - 5 } & $\begin{array}{l}\text { Capability } \\
\text { development }\end{array}$ & $\begin{array}{l}\text { To leverage core competencies } \\
\text { and existing resources and } \\
\text { capabilities }\end{array}$ & $\begin{array}{l}\text { To work with alliance partners } \\
\text { to develop products and fill the } \\
\text { gaps with customers }\end{array}$ \\
\hline
\end{tabular}

Source Hui (2014)

Though business model studies have gained importance, some scholars (Zott et al. 2011) observe that: (i) the definition of a business model is not clear, (ii) the researchers are interested in business models for e-business/digital business and how business models are creating competitive advantages, and (iii) researchers are considering a business model as a new unit of analysis and partners play an important role. For industrial businesses, firms must develop value creation capabilities (such as offering service-based business models, freemium-based subscription models) and business models must include contributions from partners. Though industrial businesses are going through technological innovation, they do not guarantee business success; the new product development efforts should be coupled with a new business model to capture value for its customers (Teece 2010).

Digital technologies have led to the disruption of existing business models (Weill and Woerner 2015). Corporate digital entrepreneurs in innovative companies take advantage of new business opportunities and enhance or disrupt the existing business models (e.g., Instagram, a Facebook company, disrupted Kodak's business model of capturing, sharing, and storing photography, Lucas and Goh 2009). Similarly, a big retailer, Ikea is implementing digital technologies (augmented reality AR, virtual reality $\mathrm{VR}$, big data analysis, etc.) and developing new customer-centric business models (Milne 2018). Ibarra et al. (2017) suggested four different ways in which digital entrepreneurs in existing companies are transforming their business models by leveraging digital technologies: internal and external process optimization by applying digital technologies in existing businesses; improving customer interfaces with digital technologies and offering new business models; developing new ecosystems and value networks by integrating 
companies' business processes with ecosystem partners and offering new products and services; developing disruptive new smart products and services and creating new business models.

Based on these discussions, we propose that digital technologies lead to business model transformations, which in turn influence corporate digital entrepreneurs to develop new products and services for their organizations.

\subsection{Operating Model Transformation}

Business model transformation may not be enough for corporate digital entrepreneurship and companies need to transform their existing operating models or develop new operating models for innovation and operational efficiencies. The digital operating model is a new way of running business functions, processes, and structures that combines digital technologies and operational capabilities of an organization so that it can achieve its mission (WEF 2018). Companies can achieve operational efficiencies and competitive advantages by understanding current and emerging business processes, models and current and emerging digital technologies (Andriole 2017). Organizations should develop the following capabilities to transform their operations digitally (WEF 2018) to initiate new ventures.

- To sense disruption and extend industry boundaries: Since physical and digital worlds are converging, companies should develop an operating model that will expand beyond their current industry. Corporate digital entrepreneurs should explore business opportunities outside their current business boundaries. As firms now have temporary competitive advantages (McGrath 2013) as more competitors are entering the business from multiple industries, to remain competitive, a firm needs to transform its operating model and expand its industry boundaries.

- To experiment with ideas and launch them faster: Corporate digital entrepreneurs should launch their ideas faster and should try to get early mover's advantage with their products and services. Digital entrepreneurs should take advantage of platform-based innovations and open systems (Hsieh et al. 2019).

- To understand and leverage data: Corporate digital entrepreneurs should understand their data and should come up with operating models to monetize data in new ways and which may lead to new business. The data monetization capability is gaining importance. Data monetization is the conversion of the intangible value of data into real value by selling the data, and it can also be monetized in other forms, like data-driven advertising or discounts and reduction in IT costs (Najjar and Kettinger 2013). For example, GE and Pivotal created a 
data lake for the airline industry by storing flight data from the aircraft and providing analytics to airlines. ${ }^{11}$ Thus, a data-driven operating model may foster corporate digital entrepreneurship.

- To build a competent digital team: Companies should assess their digital capabilities and acquire new or retrain existing workforce in digital technologies. The managerial cognitive capability (Helfat and Peteraf 2014) is essential for managers who are faced with strategic changes for corporate digital entrepreneurship. The role of Chief Digital Officer (CDO) is critical for corporate digital entrepreneurship, and this person is responsible for digital initiatives in large organizations (Singh and Hess 2017).

- To develop ecosystem partnerships: Corporate entrepreneurs should develop ecosystem partnerships to provide comprehensive solutions to their customers. Also, companies should partner for non-core activities. The firm with stronger technological capabilities likes to enter an emerging technological field through internal development, whereas the firm with weaker technological capabilities will enter through strategic alliances (Anand et al. 2010). In order to successfully launch new products and services, a firm often cannot fulfill all the requirements from customers on its own, so the strategic partnership is key for success and corporate digital entrepreneurs should take advantage of that.

- To organize for speed: Companies should have digitally savvy executives who can lead corporate digital entrepreneurship. The role of CDO reporting to the CEO could be ideal for companies. In a hyper-competitive environment (digital disruption), the mere presence of adequate resources is not enough and the firm's ability to mobilize its resources and organizational capabilities and align them dynamically with the changing opportunities in the environment is vital to maintain competitive advantage (Liao et al. 2009). The role of the CDO to bring changes using digital technologies is a key for corporate digital entrepreneurship (Rickards et al. 2015).

- To design a user-friendly experience for its customers: Corporate digital entrepreneurs should design multi-channel user experiences for their customers, which should include web, mobile, and other digital assistants. Omni-channel marketing capabilities are gaining importance to connect with the customers and becoming a key success factor for developing new products and services for a firm (Mirsch et al. 2016).

Industry 4.0 or the Fourth Industrial Revolution refers to the next phase of the digitization of manufacturing where emerging technologies, such as IoT, play a significant role which has the potential to develop low volume highly personalized products and services cost-effectively (Bahrin et al. 2016). According to Fonseca (2018), Industry 4.0 fosters newer production systems and business models impacting the overall manufacturing value chain, society, and environment. The Fourth Industrial Revolution will empower consumers and will foster new business models, and digitally enabled consumer-obsessed companies must change their

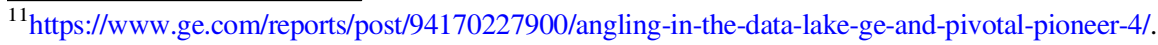


operating models to satisfy the consumers' needs. ${ }^{12}$ One of the significant changes in the operating model is driven by digitization across vertical and horizontal functions of an organization. Industrial businesses are digitizing and integrating their vertical value chains, from design, manufacturing, sales and service functions. All operational process information is available on a real-time basis, and it is supported by emerging technologies such as augmented reality (AR), virtual reality (VR), artificial intelligence, and machine learning (AI/ML). The horizontal integration spans across partners, suppliers, and customers in the digital ecosystem. The corporate digital entrepreneurs are developing new operating models to support pay-per-use business models. For example, Baker Hughes (a GE Company) has developed digital twins in their Minden plant to optimize supply chain and factory operations. ${ }^{13}$ Digital Twins are virtual models of physical assets or business processes that learn continuously from the data; they provide proactive business decisions and use emerging digital technologies such as IoT, Big Data, AI/ML, 3D simulation, and other technologies. The corporate digital entrepreneurs are also forging strategic alliances and bringing new products and services to the market. For example, GE Aviation and Microsoft are developing a new outcome-centric business model, "TrueEngine", where GE Aviation will use Microsoft's Blockchain technology and offers a cloud-based service so that airline companies can get better visibility of their entire supply chains, which in turn will improve their operational efficiencies (Allison 2019). Thus, strategic ecosystem-centric operating models are helping digital entrepreneurs to develop new products and services.

Based on these discussions, the framework proposes that digital technologies influence operating model transformation and foster corporate digital entrepreneurship.

\subsection{Cultural Transformation}

Business model transformation and operating model transformation are two key factors for corporate digital entrepreneurship. However, another key factor is cultural transformation. To implement Industry 4.0, the companies will face organizational challenges related to digital culture and training as all employees need to think and act like digital natives, should have the willingness to experiment with new technologies and new ways to do their work (Lee et al. 2017). In the new digital age, business leaders must have the ability to reimagine their businesses with clear digital strategies and to foster digital cultures in their organizations (Kane et al. 2015).

Most companies are facing digital talent and skill challenges, and they need to develop digital workforces by improving their company culture and offering

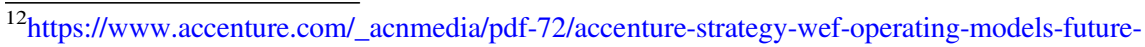
consumption-full-report.pdf.

${ }^{13} \mathrm{https}$ //gereportsbrasil.com.br/how-digital-twin-is-making-machines-and-processes-moreproductive-a4d1b6ef4ddc.
} 
suitable incentives and growth opportunities for their digital workforce. Corporate digital entrepreneurs should pay special attention to the following challenges for developing new products and services:

- Attracting and retaining talent: Corporate digital entrepreneurs should develop proper recruitment and retention strategies for their employees. Companies also need to have transparent hiring policies because digitally savvy applicants receive information from different online channels, such as Glassdoor and Linkedin.com, and any negative comments might impact on selecting and retaining talent. Employee satisfaction is also associated with long-term returns, profitability, and valuation of the companies in countries with high labor market flexibility (Edmans et al. 2014). Creating and sensing opportunities are not uniformly distributed among employees or throughout the organization, and employees need to have the capability and knowledge to recognize and execute these opportunities (Teece 2007; Nonaka and Toyama 2007). Thus, a digitally savvy and knowledgeable workforce possesses the necessary capabilities for sensing and seizing opportunities and works with internal and external partners to execute those opportunities.

- Creating a digital workforce: Due to the shortages of the digitally skilled and digitally equipped workforce, companies should develop strategies and capabilities to acquire digitally trained employees from within and outside their companies. Digital success is not all about technology. However, organizations with digital maturity are four times more likely to provide the necessary digital skills to their employees for DT (Kane et al. 2015). Organizations should assess their digital needs and develop proper training and development programs for their employees, including digital boot camps, in-house training and should encourage employees to participate in the educational courses outside the company. Companies should also prepare an inventory of existing employee skills and encourage hidden talent within the company to pursue corporate digital entrepreneurships (WEF 2018).

- Bringing in a digital leadership team: Companies may not have digitally skilled and equipped managers and need to hire digital managers from within or outside the organization so that they can initiate changes in the organization; these individuals should be placed in different functions in the organization to enable changes on a broader scale, not restricted to one business function. The top managers in a company must work as catalysts for digital corporate entrepreneurship. Top managers' entrepreneurial and leadership skills can help an organization in its transformation journey (Teece 2010).

- Moving away from a risk-averse culture to more entrepreneurial approaches: Due to digital disruption, companies should experiment with newer and bolder ideas to bring changes. According to Teece (2009), risk-averse managers tend to discount outcomes that are improbable and go after certain outcomes. For corporate digital entrepreneurship, entrepreneurial capability, such as risk-taking, is becoming a necessity as more digital companies are taking risks to venture into new areas of business (Kane et al. 2015). The role of middle 
managers is also important for driving innovation in an organization. Middle managers must allocate resources for innovative projects in organizations, and they play innovative roles in these organizations (Engle et al. 2017).

Digital technologies are forcing existing organizations to change their organizational cultures and develop a nimbler entrepreneurship-focused organization (Porter and Heppelmann 2015). Bilgeri et al. (2017) have identified three organizational and cultural issues for corporate digital entrepreneurship in large organizations: the role of new corporate entities, the role of traditional information technology (IT) functions, and business unit (BU) collaborations. More and more large organizations are creating a Chief Digital Officer (CDO) role as a key executive leadership role to drive corporate digital entrepreneurship. The role of IT is changing and the role of Chief Information Officer (CIO) is to help the CDO in new innovative projects. The business units incorporate customer success management mandates in their corporate objectives as companies and customers are collaborating for new business ventures. Most of the major organizations have CDOs as executive management roles. For example, Samsung, Nike, GE, Hitachi, etc., have $\mathrm{CDO}$ roles in their executive organizations. A CDO in a large organization works as a digital entrepreneur and is supported by a proper organization structure and digital culture to accelerate new digital business opportunities.

Based on these discussions, the framework proposes that digital technologies are influencing cultural transformation in the organizations and facilitating corporate digital entrepreneurship.

\subsection{Factors Affecting Corporate Digital Entrepreneurship}

The framework suggests that environmental turbulence (technology turbulence and market turbulence) influences the relationship between digital technologies and corporate digital entrepreneurship because environmental turbulence creates new digital business opportunities. Some scholars (Wilden and Gudergan 2015) suggest that technological capabilities such as implementing digital technologies enhance performance in stable competitive environments and marketing capabilities such as developing new business plans, go-to-market strategies, and enhance performance in highly competitive environments. Huang et al. (2012) find that technology turbulence positively affects the relationship between external technology acquisition and firm performance and not external technology exploitation and firm performance. So, digital disruptions and rapid technological changes affect corporate digital entrepreneurship as it helps organizations to develop new products and services. Environmental turbulence also influences cultural transformation. A top management team can be considered as the information processing center of an organization (Thompson 1967). Haleblian and Finkelstein (1993) suggest that the degree of environmental turbulence or stability greatly influences the information processing requirements of a top team (managers). So, environmental turbulence influences the use of managerial capabilities of top managers in a turbulent 
technology and market environment and their capability for corporate digital entrepreneurship. Another important characteristic of a digital manager is the manager's perception of the need for change as in a stable environment a manager perceives the environment as predictable and that there is less need for change, whereas, in a turbulent environment, the manager perceives it as fast-paced, unpredictable and that the need for change is very high (Ambrosini et al. 2009). In his book, The Innovator's Dilemma, Christensen (1997) argues that the organization needs to align differently when faced with technology disruption and changing market conditions. Christensen further suggests that corporate digital entrepreneurs need to have exploration and exploitation strategies in these disruptive situations. However, the firm needs to consider its existing capabilities and systematically develop new strategies and capabilities for exploration and exploitation for developing new products and services. Competitive turbulence refers to the degree of competition in an industry (Porter 1985). When the market is highly competitive, the companies must watch out for their competitors and their relative positioning in the market (Han et al. 1998). The digital business is highly competitive, and companies are coming from different industries to get a share in digital businesses. Based on these discussions, it could be suggested that the external environment influences the relationship between digital technologies and corporate digital entrepreneurship.

Internal factors, such as path dependency and digital commitment, affect corporate digital entrepreneurship. Path dependency is a property of a system where the outcomes over a period are determined by the initial set of conditions (Goldstone 1998). Path dependency can speed up, slow down or halt construction of capabilities which could better position the firm for corporate digital entrepreneurship (Sydow et al. 2009). Path dependency is developed when contingent events trigger self-reinforcing paths (i.e., the set of positive and negative mechanisms which increase the attractiveness of a path related to other paths) (Vergne and Durand 2011). These scholars also suggest that path dependency creates a lock-in within a firm. A firm may not be able to sense the opportunity and may remain on its historic path during this disruption. For example, though Blackberry realized that the mobile application market was changing drastically from a mobile phone for the conversation to a multi-purpose mobile device for conversation, audio and video, due to path dependency it did not change its original path/business and lost business. So, path dependency for Blackberry created a negative effect on corporate digital entrepreneurship. Strategic focus and intent create digital commitment for a firm, and it accelerates the development of corporate digital entrepreneurship. For example, the Board of Directors of GE, including the previous chairman Jeff Immelt, ${ }^{14}$ were committed to the digital transformation of GE's businesses by leveraging digital technologies and they established GE Digital as among the top ten software companies in the world. Adner and Helfat (2003) propose that within a single industry, where managers face

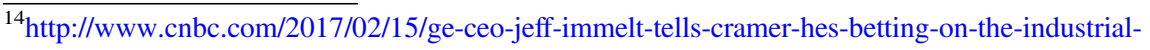
internet.html.
} 
the same external environment, time-varying corporate effects for managerial decisions are statistically significant. By extending this concept to digital commitment, it can be said that faced with digital disruptions, the commitment of managers and allocating resources will have a significant impact on corporate digital entrepreneurship. Digital commitment from the top, especially the CEO and $\mathrm{CDO}$, should enable commitment to transformation initiatives by digital technologies, and they should allocate the necessary resources to achieve that; otherwise, the transformation will be sporadic (Bendor-Samuel 2017). Thus, it is proposed that digital commitment positively influences the relationship between digital technologies and corporate digital entrepreneurship.

\section{Examples from Practice/Case Studies from Practice}

\subsection{Rolls Royce-Power by the Hour}

Rolls Royce's civil aerospace business is the leading manufacturer of aircraft engines for commercial aircraft, regional jets and the business aviation market. The company's aircraft business has a 35\% market share and revenue of 7.3B Euro in 2018. The company transformed its business model by changing a product-centric business model to an outcome-centric model, where customers pay by the operating hours of the engine. ${ }^{15}$ Previously, a customer used to pay a one-off large amount for the engine and bought a service contract for ongoing maintenance. In the engine value-based pricing model, the payment is based on flight performance hours achieved with the engine and customers do not have to buy the engines and pay the maintenance costs, thus allowing low-cost airlines to sign contracts with Rolls Royce. This innovative business model has increased its customer base and provides better benefits for customers as they only pay for engine performance.

Rolls Royce started their "Total Care" business model in the mid-1990s when the company introduced a new venture, "Total Care Term", where customers signed up for coverage over a fixed fee per engine flight hours. The fees were charged based on the expected number of shop visits and related costs divided by the expected number of flight hours. Though there were uncertainties about the engine conditions at the end of the contract, customers chose this term for the lowest cost. In 2007, Rolls Royce enhanced the existing maintenance service venture and introduced "Total Life". As the company gained more and more experience in servicing aircraft, it introduced a new service business model to increase its market share in the aircraft maintenance business. In the "Total Life" model, Rolls Royce provides aircraft maintenance for life (as long as the aircraft is in operation) and the flying hours are considered for per-hour cost; the service can be transferred to other aircraft operators in case of any changes in ownership. In 2015, Rolls Royce introduced the "Total Care Flex" business model, where a customer can pay a

\footnotetext{
${ }^{15} \mathrm{https}: / /$ www.rolls-royce.com/media/our-stories/discover/2017/totalcare.aspx.
} 
higher per -hour cost for flexibility. The business model "Total Care" helps the company to reduce waste and optimize resource efficiency while it enables customers to maximize the flying hours of their aircraft. Rolls Royce monitors the performance of the aircraft engines by implementing an IoT-based real-time data collection and analysis system and utilizing AI/ML and big data analytics technologies for proactive maintenance of the engines. Rolls Royce in turn has constant revenue streams by charging by the flying hours of the engines. Business model transformation such as "Total Care" drives new business ventures as Rolls Royce can provide other value-based services to the airlines and the airports.

Thus, Rolls Royce's new business models align with customers' business requirements and it can create powerful circular business models. With the usage of emerging technologies, a company can gain meaningful insights about the businesses of its customers which can lead to new business models and business ventures. This example illustrates how a company such as Roll Royce utilizes transformation technologies available at a particular time and has developed new business models, which in turn facilitated new business ventures.

\subsection{Siemens Healthineers Digital Ecosystem}

Siemens Healthineers is a healthcare company based in Munich, Germany, and is a division of Siemens AG. The company provides a wide range of imaging and diagnostic medical devices including X-ray systems, radiation oncology systems, laboratory diagnostics, and other diagnostic medical devices. In 2018, the revenue of Siemens Healthineers was 13.4B Euro with a profit of 2.3B Euro. Though the healthcare diagnostic and imaging systems collect a lot of data and most data is stored in the individual machines, it is difficult for a healthcare provider to analyze all these data together to provide a comprehensive 360-degree view of a patient. There is a lack of interoperability between different healthcare systems and machines from different vendors may not share information. Siemens initially developed a new service venture by participating in Integrating the Healthcare Enterprise (IHE) and providing healthcare data integration services to its customers. However, the service business realized that instead of providing individual integration services, Siemens could change its operating model and provide a healthcare data platform for interoperability with multiple partners and customers. Thus, Siemens Healthineers started a new venture, Healthcare Digital Ecosystem. Siemens Healthineers imaging equipment, in-vitro solutions and associated software and services cover more than 200,000 patients per hour globally; the data from the patients could be collected in a cloud-based digital ecosystem and analyzed using emerging technologies such as AI/ML, big data and IIoT for better patient diagnosis. The digital platform-based economy is not new and companies such as Amazon, eBay, Facebook, Google, Salesforce, and others have developed new businesses leveraging digital platforms. The platforms are frameworks that allow multiple parties to collaborate, most often creating a de-facto standard and form an ecosystem for value creation and culture (Kenney and Zysman 2015). The digital 
service providers can scale internationally by leveraging digital platforms and can develop new business ventures in different geographies (Täuscher and Laudien 2018). The healthcare digital platform links healthcare experts together, and they can communicate with their peers worldwide and exchange views and expertise for medical diagnostics, which in turn help patients and healthcare providers since population health could improve by such collaboration. A platform is successful once it has a critical mass of partners who use the platform to develop new business ventures by leveraging data from the platform. The healthcare digital ecosystem platform allows healthcare device manufacturers, healthcare payers, providers, and service providers to integrate their services seamlessly into the platform. Siemens has signed up a large number of partners to collaborate effectively in the digital platform. Currently, the platform supports data transparency across imaging systems, maintenance and performance of assets, laboratory process automation, actionable analytics from diagnosis, and imaging software platforms for multimodality reading.

Siemens has transformed its service operating model by leveraging emerging technologies such as cloud, IoT, AI/ML, big data and developed new platform-based service operations, and it helped to create new business ventures not only for Siemens but also for its ecosystem partners. The influence of emerging technologies initiates operating model transformation of an existing business and fosters entrepreneurship within the organization.

\subsection{GE Digital}

Cultural transformation is another key component for corporate digital entrepreneurship, and it is highly influenced by digital disruptions and digital technologies. Business model transformation and operating model transformation influenced by emerging technologies may not be sufficient for digital entrepreneurship without transforming the culture of the organization. The GE Digital example illustrates that.

Digital transformation is not about the digitization of existing business but rather to transform products and services to software-defined assets and to utilize these digital assets to redefine the business (Govindarajan and Immelt 2019). GE is a big industrial conglomerate, and in 2010, it operated major businesses such as aviation, healthcare, energy, oil and gas, transportation, home and business solutions and GE Capital, with a revenue of $\$ 149.59 \mathrm{~B}$. GE businesses sold industrial equipment and service contracts (to maintain that equipment) to their customers. The contribution of service revenue from those contracts was 58.5\% in 2010 (GE Annual Report 2011). GE's executives realized that GE could increase their earnings from service contracts by making their machines "Smart Machines". However, the software service business was dominated by software service providers such as IBM, Toshiba, HP, and industrial businesses such as GE, Siemens, and others were not aggressively engaged in digital initiatives. Most of the industrial companies were relying on software service providers, and they outsourced their digital operations 
to many software vendors. Also, the average gross profit margin from the manufacturing industry is around $10-15 \%,{ }^{16}$ whereas for the software industry, the median gross profit margin is around $30-40 \% .^{17}$ By analyzing the trend, GE management decided that investing in digital initiatives would be a game-changer for them as it could take the company to the next level of higher profitability and revenue. GE management also realized that GE was an industrial company, and though it had significant software revenues from different businesses, the culture of the company was not suitable for a pure-play software company. To transform the business culturally and to transform the company into a digital industrial company by leveraging IIoT, GE decided to create a new business venture, GE Digital in Silicon Valley, California, far away from its headquarters in upstate New York. GE also launched an advertising campaign, where a recent college graduate (Owen) was breaking the news to his parents and friends that he had joined GE. In one advertisement, Owen's friends were very excited and in another advertisement, Owen's father told Owen that he was not macho enough to work for an industrial manufacturing company (Winig 2015). GE wanted to reposition itself to recruit Millennials. As industrial Internet footprints were expanding in GE, the management decided to create a new role, Chief Digital Officer (CDO), in all GE businesses. The CDOs of the respective business groups reported to the group CDO of GE, and he was also the CEO of GE Digital. This matrix structure allowed the CDO of GE to influence each business in its digital ventures. Since there was a strong strategic focus and intent to transform GE businesses digitally, all business CDOs started implementing GE's digital platform "Predix" as their base digital platform for new businesses. Thus, GE implemented a strong digital culture and developed new business ventures for its different business groups.

\section{Conclusion and Implications}

Emerging digital technologies are disrupting businesses, and companies are increasingly accelerating their corporate digital entrepreneurship initiatives. This is not only true for start-up or small companies but equally important for large organizations as they need to transform their businesses and remain competitive in the market. Managers can develop new business, and operating models by leveraging digital technologies and coming up with new products are services that were not possible earlier. Cultural changes are critical to orchestrating structural changes in the organization. A proper sensing strategy is a prerequisite to understanding the internal and external environments for corporate digital entrepreneurship opportunities which are influenced by digital technologies. Once opportunities are identified, digital commitment is necessary to support these initiatives by allocating proper resources and implementing suitable operating models to seize those

\footnotetext{
${ }^{16} \mathrm{https}: / /$ smallbusiness.chron.com/average-manufacturers-gross-profit-percent-15827.html.

${ }^{17} \mathrm{https}$ //www.inc.com/graham-winfrey/the-5-most-profitable-industries-in-the-us.html.
} 
opportunities. Companies should also provide learning and development opportunities for their employees to become digital employees. Ecosystem partnership is very important and a company cannot provide the entire business solution, so strategic alliances and customer management are critical for corporate digital entrepreneurship.

As larger organizations are implementing digital technologies to foster corporate digital entrepreneurship, they can identify potential business ventures to strengthen their competitive positioning in the market. For industrial businesses, product-as-service business models could be piloted for newer products and services. The organizations can develop joint go-to-market (GTM) strategies with alliance partners to address customer requirements. Corporate digital entrepreneurship must be a corporate mandate and a proper organization structure, headed by a CDO or Chief Information Officer (CIO), could foster corporate digital entrepreneurship.

\section{References}

Abd Aziz, S., Fitzsimmons, J. R., \& Douglas, E. J. (2008). Clarifying the business model construct.

Adner, R., \& Helfat, C. E. (2003). Corporate effects and dynamic managerial capabilities. Strategic Management Journal, 24(10), 1011-1025.

Allison, I. (2019). Codename 'TrueEngine:' GE aviation and microsoft reveal aircraft parts certification blockchain. From https://finance.yahoo.com/news/codename-truengine-geaviation-microsoft-153044786.html.

Ambrosini, V., Bowman, C., \& Collier, N. (2009). Dynamic capabilities: An exploration of how firms renew their resource base. British Journal of Management, 20(S1), S9-S24.

Anand, J., Oriani, R., \& Vassalo, R.S. (2010). Alliance activity as a dynamic capability in the face of a discontinuous technological change. Organization Science, 1213-1232.

Andriole, S. (2017). Is digital privacy a right or a privilege? MIT Sloan Management Review, Spring 2017 issue.

Antoncic, B., \& Hisrich, R. D. (2001). Intrapreneurship: Construct refinement and cross-cultural validation. Journal of Business Venturing, 16(5), 495-527.

Augusto, J. C., McCullagh, P., McClelland, V., \& Walkden, J. A. (2007, November). Enhanced healthcare provision through assisted decision-making in a smart home environment. In $2 n d$ Workshop on Artificial Intelligence Techniques for Ambient Intelligence.

Bahrin, M. A. K., Othman, M. F., Azli, N. N., \& Talib, M. F. (2016). Industry 4.0: A review on industrial automation and robotic. Jurnal Teknologi, 78(6-13), 137-143.

Berman, S. J., \& Hagan, J. (2006). How technology-driven business strategy can spur innovation and growth. Strategy \& Leadership, 34(2), 28-34.

Bilgeri, D., Wortmann, F., \& Fleisch, E. (2017). How digital transformation affects large manufacturing companies' organization.

Bendor-Samuel, P. (2017). How to eliminate enterprise shadow IT. CIO.

Bollard, A., Larrea, E., Singla, A., \& Sood, R. (2017, March). The next-generation operating model for the digital world. Digital McKinsey.

Burmeister, C., Lüttgens, D., \& Piller, F. T. (2016). Business model innovation for Industrie 4.0: Why the "Industrial Internet" mandates a new perspective on innovation. Die Unternehmung, $70(2), 124-152$.

Christensen, C. (1997). The Innovator's Dilemma: When new technologies cause great forms to fall (p. 1997). Boston, MA: Harvard Business School Press. 
Christensen, C. M., Anthony, S. D., Roth, E. A., \& Kaufman, R. (2005). Seeing what's next: Using the theories of innovation to predict industry change. Performance Improvement, 44(4), $50-51$.

Cockburn, I. M., Henderson, R., \& Stern, S. (2018). The impact of artificial intelligence on innovation (No. w24449). National Bureau of Economic Research.

Edmans, A., Li, L., \& Zhang, C. (2014). Employee satisfaction, labor market flexibility, and stock returns around the world (No. w20300). National Bureau of Economic Research.

Engle, R. L., Lopez, E. R., Gormley, K. E., Chan, J. A., Charns, M. P., \& Lukas, C. V. (2017). What roles do middle managers play in implementation of innovative practices? Health Care Management Review, 42(1), 14.

Evans, P.C., \& Annunziata, M. (2012, November). Industrial Internet: Pushing the boundaries of minds and machines. From http://www.ge.com/docs/chapters/Industrial_Internet.pdf.

Finkelstein, S., Hambrick, D. C., \& Cannella, A. A. (2009). Strategic leadership: Theory and research on executives, top management teams, and boards. Strategic Management (Oxford U.).

Fonseca, L. M. (2018, May). Industry 4.0 and the digital society: Concepts, dimensions and envisioned benefits. In Proceedings of the international conference on business excellence (Vol. 12, No. 1, pp. 386-397). Sciendo.

GE Annual Report. (2011). From https://www.ge.com/sites/default/files/GE_AR11_EntireReport. pdf.

Giones, F., \& Brem, A. (2017). Digital technology entrepreneurship: A definition and research agenda. Technology Innovation Management Review, 7(5).

Goldstone, J. A. (1998). Initial conditions, general laws, path dependence, and explanation in historical sociology. American Journal of Sociology, 104(3), 829-845.

Govindarajan, V., \& Immelt, J. R. (2019). The only way manufacturers can survive. MIT Sloan Management Review, 60(3), 24-33.

Gustavsson, A. K., Petrov, P. N., Lee, M. Y., Shechtman, Y., \& Moerner, W. E. (2018). 3D single-molecule super-resolution microscopy with a tilted light sheet. Nature Communications, 9(1), 123.

Hafezieh, N., Akhavan, P., \& Eshraghian, F. (2011). Exploration of process and competitive factors of entrepreneurship in digital space: A multiple case study in Iran. Education, Business and Society: Contemporary Middle Eastern Issues, 4(4), 267-279.

Hair, N., Wetsch, L. R., Hull, C. E., Perotti, V., \& Hung, Y. T. C. (2012). Market orientation in digital entrepreneurship: advantages and challenges in a Web 2.0 networked world. International Journal of Innovation and Technology Management, 9(06), 1250045.

Haleblian, J., \& Finkelstein, S. (1993). Top management team size, CEO dominance, and firm performance: The moderating roles of environmental turbulence and discretion. Academy of Management Journal, 36(4), 844-863.

Han, J. K., Kim, N., \& Srivastava, R. K. (1998). Market orientation and organizational performance: Is innovation a missing link? The Journal of Marketing, 30-45.

Hanson, C. W., \& Marshall, B. E. (2001). Artificial intelligence applications in the intensive care unit. Critical Care Medicine, 29(2), 427-435.

Helfat, C. E., \& Peteraf, M. A. (2014). Managerial cognitive capabilities and the microfoundations of dynamic capabilities. Strategic Management Journal (Early View) 1-20.

Hsieh, Y. J., \& Wu, Y. J. (2019). Entrepreneurship through the platform strategy in the digital era: Insights and research opportunities. Computers in Human Behavior, 95, 315-323.

Huang, P. Y., Ouyang, T. H., Pan, S. L., \& Chou, T. C. (2012). The role of IT in achieving operational agility: A case study of Haier. China. International Journal of Information Management, 32(3), 294-298.

Hughes, M., \& Mustafa, M. (2017). Antecedents of corporate entrepreneurship in SMEs: Evidence from an emerging economy. Journal of Small Business Management, 55, 115-140.

Hui, G. (2014, July). How the Internet of Things changes business models. Harvard Business Review. 
Hull, M. E., Farmer, F. R., \& Perelman, E. S. (2007). U.S. Patent No. 7,269,590. Washington, DC: U.S. Patent and Trademark Office.

Ibarra, D., Igartua, J. I., \& Ganzarain, J. (2017). Business model innovation in industry 4.0: the case of a university-industry experience in SMES. In Inted 2017 Proceedings.

Kaganer, E., Sieber, S., \& Zamora, J. (2014). The 5 keys to a digital mindset. IESE. From http:// www.forbes.com/sites/iese/2014/03/11/the-5-keys-to-a-digital-mindset/2/\#47c6c5e94f5f.

Kagermann, H., Riemensperger, F., Hoke, D., Helbig, J., Stocksmeier, D., Wahlster, W., et al. (2014). Smart service welt: Recommendations for the strategic initiative web-based services for businesses. Berlin: Acatech-National Academy of Science and Engineering.

Kane, G. C., Palmer, D., Phillips, A. N., Kiron, D., \& Buckley, N. (2015, July). Strategy, not technology, drives digital transformation. MIT Sloan Management Review.

Kenney, M., \& Zysman, J. (2015, June). Choosing a future in the platform economy: The implications and consequences of digital platforms. In Kauffman Foundation New Entrepreneurial Growth Conference (Vol. 156160).

Knight, G. A. (1997). Cross-cultural reliability and validity of a scale to measure firm entrepreneurial orientation. Journal of Business Venturing, 12(3), 213-225.

Kirzner, I. (1985). Discovery and capitalist process. Chicago: The University of Chicago Press.

Kohli, R., \& Grover, V. (2008). Business value of IT: An essay on expanding research directions to keep up with the times. Journal of the Association for Information Systems, 9(1), 1.

Kraus, S., Burtscher, J., Vallaster, C., \& Angerer, M. (2018). Sustainable entrepreneurship orientation: A reflection on status-quo research on factors facilitating responsible managerial practices. Sustainability, 10(2), 444.

Krotov, V. (2017). The Internet of Things and new business opportunities. Business Horizons, 60 (6), 831-841.

Leber, J. (2012). General Electric Pitches an Industrial Internet. MIT Technology Review, November 2012.

Lee, I., \& Lee, K. (2015). The Internet of Things (IoT): Applications, investments, and challenges for enterprises. Business Horizons, 58(4), 431-440.

Lee, M. X., Lee, Y. C., \& Chou, C. J. (2017). Essential implications of the digital transformation in industry 4.0.

Liao, J., Kickul, J. R., \& Ma, H. (2009). Organizational dynamic capability and innovation: An empirical examination of internet firms. Journal of Small Business Management, 47(3), 263286.

Ling, Y. A. N., Simsek, Z., Lubatkin, M. H., \& Veiga, J. F. (2008). Transformational leadership's role in promoting corporate entrepreneurship: Examining the CEO-TMT interface. Academy of Management Journal, 51(3), 557-576.

Lucas Jr, H. C., \& Goh, J. M. (2009). Disruptive technology: How Kodak missed the digital photography revolution. The Journal of Strategic Information Systems, 18(1), 46-55.

Mahadevan, B. (2000). Business models for internet-based E-commerce: An anatomy. California Management Review, 42(4), 55-69

McGrath, R. G. (2013). The end of competitive advantage. Boston, MA: Harvard Business Review Press.

Milne, R. (2018). Ikea vows "transformation" as it reshapes business models. From https://www.ft. com/content/1a66c838-3cc1-11e8-b7e0-52972418fec4.

Mirsch, T., Lehrer, C., \& Jung, R. (2016). Channel integration towards omnichannel management: A literature review.

Mithas, S., Tafti, A., \& Mitchell, W. (2013). How a firm's competitive environment and digital strategic posture influence digital business strategy. In MIS quarterly (pp. 511-536).

Morris, M. H., Kuratko, D. F., \& Covin, J. G. (2010). Corporate entrepreneurship \& innovation. Cengage Learning.

Nambisan, S., Lyytinen, K., Majchrzak, A., \& Song, M. (2017). Digital innovation management: Reinventing innovation management research in a digital world. MIS Quarterly, 41(1). 
Najjar, M. S., \& Kettinger, W. J. (2013). Data Monetization: Lessons from a retailer's journey. MIS Quarterly Executive, 12(4).

Nonaka, I., \& Toyama, R. (2007). Why do firms differ? The theory of the knowledge-creating firm. In: Knowledge creation and management. New challenges for managers (pp. 13-31).

Ping, W. L., Jie, J., Naiqiu, L., \& Zhengzhong, X. (2010). A review and prospects of research on human resource management of intrapreneurship. In 2010 IEEE International Conference on Advanced Management Science (ICAMS 2010).

Porter, M. E. (1985). Competitive advantage: Creating and sustaining superior performance. New York: Free Press, 43, 214.

Porter, M. E., \& Heppelmann, J. E. (2015). How smart, connected products are transforming companies. Harvard Business Review, 93(10), 96-114.

Rayna, T., \& Striukova, L. (2016). From rapid prototyping to home fabrication: How 3D printing is changing business model innovation. Technological Forecasting and Social Change, 102, 214-224.

Reijnen, C., Overbeek, S., Wijers, G. M., Sprokholt, A., Haijenga, F., \& Brinkkemper, S. (2018). A shared vision for digital transformation: Codification of the operating model canvas approach.

Rickards, T., Smaje, K., \& Sohoni, V. (2015). Transformer in chief: The new chief digital officer. McKinsey\&Company.

Setia, P., Setia, P., Venkatesh, V., \& Joglekar, S. (2013). Leveraging digital technologies: How information quality leads to localized capabilities and customer service performance. MIS Quarterly, 565-590.

Schneider, S. (2014). GE Shores Up Saving with a Data Lake. VmWare Tanzu Blog. From https:// tanzu.vmware.com/content/blog/ge-shores-up-savings-for-aviation-with-a-data-lake.

Schumpeter, J. A. (1934). Change and the entrepreneur. Essays of JA Schumpeter.

Singh, A., \& Hess, T. (2017). How chief digital officers promote the digital transformation of their companies. MIS Quarterly Executive, 16(1).

Smith, W. K., \& Tushman, M. L. (2005). Managing strategic contradictions: A top management model for managing innovation streams. Organization Science, 16(5), 522-536.

Stopford, J. M., \& Baden-Fuller, C. W. (1994). Creating corporate entrepreneurship. Strategic Management Journal, 15(7), 521-536.

Sund, K. J., Bogers, M., Villarroel, J. A., \& Foss, N. (2016). Managing tensions between new and existing business models. MIT Sloan Management Review, 57(4), 8.

Sussan, F., \& Acs, Z. J. (2017). The digital entrepreneurial ecosystem. Small Business Economics, $49(1), 55-73$.

Sydow, J., Schreyögg, G., \& Koch, J. (2009). Organizational path dependence: Opening the black box. Academy of Management Review, 34(4), 689-709.

Täuscher, K., \& Laudien, S. M. (2018). Understanding platform business models: A mixed methods study of marketplaces. European Management Journal, 36(3), 319-329.

Thompson, E. P. (1967). Time, work-discipline, and industrial capitalism. Past \& Present, 38, 56-97.

Teece, D. J. (2007). Explicating dynamic capabilities: The nature and microfoundations of (sustainable) enterprise performance. Strategic Management Journal, 28, 1319-1350.

Teece, D. J. (2009). Dynamic capabilities and strategic management: Organizing for innovation and growth. Oxford University Press on Demand.

Teece, D. J. (2010). Business models, business strategy and innovation. Long Range Planning, 43 (2-3), 172-194.

Turban, E., King, D., Lee, J., Warkentin, M., \& Chung, M. H. (2006). E-commerce: A managerial perspective. Low Price Edition, 180-183.

Tripsas, M., \& Gavetti, G. (2000). Capabilities, cognition, and inertia: Evidence from digital imaging. Strategic Management Journal, 21(10-11), 1147-1161.

Vergne, J. P., \& Durand, R. (2011). The path of most persistence: An evolutionary perspective on path dependence and dynamic capabilities. Organization Studies, 32(3), 365-382. 
Ward, T., \& Baruah, B. J. (2014, September). Enhancing intrapreneurial skills of students through entrepreneurship education: A case study of an interdisciplinary engineering management programme. In 13th International Conference on Information Technology based Higher Education and Training (ITHET) (pp. 1-6). IEEE.

Weill, P., \& Woerner, S. L. (2015). Optimizing your digital business model. MIT Sloan Management Review 53(3), 28-36.

Wilden, R., \& Gudergan, S. P. (2015). The impact of dynamic capabilities on operational marketing and technological capabilities: investigating the role of environmental turbulence. Journal of the Academy of Marketing Science, 43(2), 181-199.

Winig, L. (2015, February). GE's Big Bet on data and analytics. MIT Sloan Management Review.

World Economic Forum. (WEF, 2018, May). The future of jobs: Employment, skills and workforce strategy for the fourth industrial revolution. From URL: http://reports.weforum.org/ digital-transformation/wp-content/blogs.dir/94/mp/files/pages/files/dti-executive-summary20180510.pdf.

Zahra, S. A. (1991). Predictors and financial outcomes of corporate entrepreneurship: An exploratory study. Journal of Business Venturing, 6(4), 259-285.

Zahra, S. A. (1993). A conceptual model of entrepreneurship as firm behavior: A critique and extension. Entrepreneurship theory and practice, 17(4), 5-21.

Zott, C., Amit, R., \& Massa, L. (2011, May). The business model: Recent developments and future research. Journal of Management.

Open Access This chapter is licensed under the terms of the Creative Commons Attribution 4.0 International License (http://creativecommons.org/licenses/by/4.0/), which permits use, sharing, adaptation, distribution and reproduction in any medium or format, as long as you give appropriate credit to the original author(s) and the source, provide a link to the Creative Commons license and indicate if changes were made.

The images or other third party material in this chapter are included in the chapter's Creative Commons license, unless indicated otherwise in a credit line to the material. If material is not included in the chapter's Creative Commons license and your intended use is not permitted by statutory regulation or exceeds the permitted use, you will need to obtain permission directly from the copyright holder.

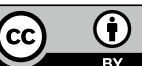

